Editor's Note: These short reviews of recent JNeurosci articles, written exclusively by students or postdoctoral fellows, summarize the important findings of the paper and provide additional insight and commentary. If the authors of the highlighted article have written a response to the Journal Club, the response can be found by viewing the Journal Club at www.jneurosci.org. For more information on the format, review process, and purpose of Journal Club articles, please see http://www.jneurosci.org/content/ jneurosci-journal-club.

\title{
Clarifying the Role of the Rostral Interpeduncular Nucleus in Aversion to Nicotine
}

\author{
Julia K. Brynildsen \\ Neuroscience Graduate Group, Perelman School of Medicine, University of Pennsylvania, Philadelphia, Pennsylvania 19104 \\ Review of Morton et al.
}

Genetic and environmental factors contribute to an individual's sensitivity to drug reward and aversion, thereby influencing their susceptibility to drug abuse and addiction. A genetic variant (D398N) in the gene CHRNA5, which encodes the $\alpha 5$ subunit of the nicotinic acetylcholine receptor (nAChR), has repeatedly been shown to influence susceptibility to nicotine abuse and heaviness of smoking in human populations (Saccone et al., 2007; Bierut et al., 2008; Stevens et al., 2008). Coinciding with these findings, in vitro studies have shown reduced calcium signaling and attenuated response to $\mathrm{AChR}$ agonists in the presence of this genetic variant (Bierut et al., 2008; Tammimäki et al., 2012). Thus, there appears to be a link between reduced function of $\alpha 5$-containing nAChRs and enhanced nicotine abuse liability associated with CHRNA5 D398N.

Among human smokers, CHRNA5 D398N reduces aversive effects of nicotine (Jensen et al., 2015). Whereas initial smoking experiences are unpleasant for most people, smokers who carry the $398 \mathrm{~N}$ variant have reported more pleasurable early smoking experiences (Sherva et al.,

\footnotetext{
Received Sept. 4, 2018; revised Nov. 2, 2018; accepted Nov. 14, 2018. This work was supported by Translational Addiction Research Fellowship Program T32-DA028874.

The authors declare no competing financial interests.

Correspondence should be addressed to Julia K. Brynildsen at jbryn@pennmedicine.upenn.edu.

https://doi.org/10.1523/JNEUROSCI.2282-18.2018

Copyright $\odot 2019$ the authors $\quad 0270-6474 / 19 / 390783-03 \$ 15.00 / 0$
}

2008). Although it has been suggested that this difference stems from altered reward processing, it is also consistent with reduced aversion encoding. Less aversive early smoking experiences are correlated with increased likelihood of continued smoking and of nicotine dependence (de Wit and Phillips, 2012). Thus, in addition to contributing to increased nicotine intake among smokers, the $398 \mathrm{~N}$ variant of CHRNA5 may also increase an individual's likelihood to continue smoking following initial exposure.

Preclinical studies in rodent models have begun to provide deeper insight into the neural mechanisms by which CHRNA5 genetic variants may influence nicotine dependence liability through effects on nicotine aversion. For example, deletion of the $\alpha 5 \mathrm{nAChR}$ subunit in rodents enhances self-administration and conditioned place preference for nicotine doses that are typically aversive (Jackson et al., 2010; Fowler et al., 2011). Furthermore, the $\alpha 5 \mathrm{nAChR}$ is expressed within the medial habenula-interpeduncular nucleus (MHb-IPN) tract, which has an important role in encoding aversive responses to nicotine. The distinct functions of the $\mathrm{MHb}$ and IPN and the neural pathways through which they exert their effects have not yet been fully delineated, however. More clearly defining the neural circuitry implicated in nicotine aversion is of critical importance, given that aversive experiences influence the likelihood that an individual will continue smoking and become nicotine-dependent following initial exposure.

Recent work by Morton et al. (2018) uses a combination of electrophysiology, optogenetics, and tract tracing in a novel mouse model to examine the role of the $\alpha 5 \mathrm{nAChR}$ subunit in the ventral $\mathrm{MHb}$ $(\mathrm{MHbV})$ and rostral IPN (IPR) and to elucidate the contribution of the IPR to behavioral aversion. Through brain slice electrophysiology experiments, Morton et al. (2018) showed, in mice lacking the $\alpha 5$ subunit, that inward currents induced by either ACh or nicotine were reduced in the IPR (Morton et al., 2018, their Fig. 1). Synaptic blockers reduced ACh-induced currents to a lesser extent, indicating that $\alpha 5$ subunit expression more strongly influences the response to ACh than glutamatergic signaling in the IPR (Morton et al., 2018, their Fig. $1 E, F)$. The effect of $\alpha 5$ subunit deletion on ACh currents was not detectable in the presence of a $\beta 2^{\star} \mathrm{nAChR}$ antagonist, suggesting that $\beta 2$-containing nAChRs strongly mediate the response to ACh within the IPR and likely associate with the $\alpha 5$ subunit (Morton et al., 2018, their Fig. 1G,H).

Although their initial experiments demonstrated that the $\alpha 5$ subunit plays a critical functional role in IPR neurons (Morton et al., 2018, their Fig. 1), it could not be concluded based on these results alone whether $\alpha 5$ subunits have the greatest effect within IPR neurons or elsewhere 
within the MHb-IPN pathway. Therefore, Morton et al. (2018) next sought to compare the impact of $\alpha 5$ subunit deletion on neuronal firing within the IPR and the $\mathrm{MHbV}$, which sends cholinergic projections to the IPR. In the absence of $\alpha 5$, nicotine-induced neuronal firing was reduced in the IPR, but not in the MHbV, indicating that IPR neurons are the source of functional alterations in this pathway that accompany loss of the $\alpha 5$ subunit (Morton et al., 2018, their Fig. 2).

Morton et al. (2018) generated a novel mouse line that enables detection of Chrna5-expressing neuron populations. Using viral tracing in these mice, the authors showed that Chrna5- and SSTexpressing neurons in the median raphe (MnR) project to IP subnuclei, including the central IP and the boundary between the intermediate and lateral IP (Morton et al., 2018, their Fig. 6). The MnR nuclei are a major source of serotonergic neurons (Dahlstroem and Fuxe, 1964) and also receive GABAergic innervation from the IPR (Hsu et al., 2013). Thus, $\alpha 5$-expressing neurons within the IPR could indirectly influence neighboring IP subnuclei through modulatory effects on MnR neurons. Further studies will be needed to investigate the influence of $\alpha 5$-expressing IPN neurons on serotonergic signaling from the MnR.

Finally, using a place preference paradigm, Morton et al. (2018) demonstrated that $2 \mathrm{~h}$ after a single exposure to nicotine, mice spent less time in a chamber paired with optogenetic stimulation of $\alpha 5$ expressing neurons in the IPN, indicating that this stimulation was aversive (Morton et al., 2018, their Fig. 11). A similar behavioral response was observed when IPN neurons had been primed with a prior optogenetic stimulation $1 \mathrm{~d}$ earlier (Morton et al., 2018, their Fig. 10). Thus, it appears that optogenetic stimulation effectively mimics the effect of acute nicotine on Chrna5-containing IPN neurons. Intriguingly, Wolfman et al. (2018) recently used a similar paradigm to demonstrate that nonspecific stimulation of IPN neurons elicits behavioral avoidance in the absence of any priming stimulus. Together, the findings of these two studies indicate that IPN-dependent aversion is not solely dependent on Chrna5-expressing neurons and that $\alpha 5$-containing receptors contribute to behavioral aversion only after sensitization by a priming stimulus.

Morton et al. (2018) contribute to a growing body of literature defining the specific regions, cell types, and receptor compositions that encode avoidant and aversive responses to nicotine. Another recent study determined that GLP-1 neurons in the nucleus tract solitarius, which plays a critical role in suppression of food intake (Hayes et al., 2011), express $\alpha 5$ containing $\mathrm{nAChRs}$ and are activated by nicotine (Tuesta et al., 2017). This study also provided evidence that GLP-1 signaling acting on the MHb-IPN circuit inhibits nicotine intake to prevent consumption of aversively high doses of nicotine (Tuesta et al., 2017). However, what role $\alpha 5$ containing nAChRs have in this avoidance signaling pathway is not entirely clear, particularly because these receptors are also expressed on other cell types in addition to GLP-1 neurons (Tuesta et al., 2017). Another recent study found that stimulation of the IPN induces behavioral avoidance and that inhibition of GABAergic projections from the IPN to the laterodorsal tegmentum (LDTg) attenuates conditioned place aversion to aversively high nicotine doses (Wolfman et al., 2018). Morton et al. (2018) observed sparse projections from IPN to LDTg in Chrna5 ${ }^{\mathrm{Cre}}$ neurons, indicating that $\alpha 5$ subunit expression within IPN neurons that project to the LDTg could mediate this effect.

Morton et al. (2018) note that their findings are not consistent with previous work in which virally expressing the $\alpha 5$ $\mathrm{nAChR}$ subunit in the habenula of $\alpha 5$ knock-out mice rescued the behavioral alterations associated with this genotype (Fowler et al., 2011). This discrepancy could be explained by methodological differences between these two studies. Fowler et al. (2011) focused on the role of $\alpha 5$ subunit expression throughout the MHb-IPN pathway in nicotine selfadministration behavior, without distinguishing the contributions of the individual regions comprising this circuit. Fowler et al. (2011) confirmed expression of $\alpha 5$ subunit mRNA in both the MHb and IPN after injecting a Lenti-CHRNA5 vector into the $\mathrm{MHb}$, as a result of Chrna5 mRNA being transported from the $\mathrm{MHb}$ to the IPN along the fasciculus retroflexus. They proposed that $\alpha 5$-containing nAChRs within the IPN are located on MHb axon terminals, where they influence nicotine intake via their effects on glutamatergic transmission in the IPN. However, the findings of Morton et al. (2018) and Hsu et al. (2013) indicate that $\alpha 5$ subunits within the MHb-IPN pathway are instead expressed postsynaptically in the IPN, on GABAergic neurons. The behavioral rescue reported in Fowler et al. (2011) could be due to changes in IPN signaling resulting from expression of Chrna5 in MHb neurons, although the virally-induced expression of $\alpha 5$ subunits in this study did not recapitulate the endogenous pattern of expression identified in more recent studies (Hsu et al., 2013; Morton et al., 2018).

Another important distinction between Fowler et al. (2011) and Morton et al. (2018) is the behavioral outputs measured following manipulation of the $\alpha 5$ subunit. In Fowler et al. (2011), knocking down $\alpha 5$ subunit expression was found to enhance self-administration of high nicotine doses, which could be the result of a higher nicotine satiety threshold. Morton et al. (2018) found that mice actively avoided a chamber paired with stimulation of $\alpha 5$ containing IPR neurons, providing strong evidence that stimulation of these neurons is aversive. Integration of these findings and other recent work is consistent with a model in which stimulation of the IPN by excitatory glutamatergic $\mathrm{MHb}$ projections signals nicotine satiety (Fowler et al., 2011; Tuesta et al., 2017), and stimulation of IPN projections to the LDTg and mesopontine raphe is critical for nicotine aversion (Morton et al., 2018; Wolfman et al., 2018).

While a number of prior studies have implicated the habenulo-interpeduncular pathway in nicotine avoidance and aversion, Morton et al. (2018) provide evidence that the functional consequences of altering $\alpha 5 \mathrm{nAChR}$ subunit expression are specific to rostral IPN neurons. This work is an important step toward identifying specific brain regions that could serve as therapeutic targets for nicotine dependence. In future studies, it will be important to further clarify the roles of serotonergic, GABAergic, and other signaling pathways in $\alpha 5$-mediated nicotine avoidance and aversion.

\section{References}

Bierut LJ, Stitzel JA, Wang JC, Hinrichs AL, Grucza RA, Xuei X, Saccone NL, Saccone SF, Bertelsen S, Fox L, Horton WJ, Breslau N, Budde J, Cloninger CR, Dick DM, Foroud T, Hatsukami D, Hesselbrock V, Johnson EO, Kramer J, et al. (2008) Variants in nicotinic receptors and risk for nicotine dependence. Am J Psychiatry 165:1163-1171. CrossRef Medline

Dahlstroem A, Fuxe K (1964) Evidence for the existence of monoamine-containing neurons in the central nervous system: I. Demonstration of monoamines in the cell bodies of brain stem neurons. Acta Physiol Scand Suppl 232 [Suppl.]1-55.

de Wit H, Phillips TJ (2012) Do initial responses to drugs predict future use or abuse? Neurosci Biobehav Rev 36:1565-1576. CrossRef Medline

Fowler CD, Lu Q, Johnson PM, Marks MJ, Kenny PJ (2011) Habenular $\alpha 5$ nicotinic receptor 
subunit signalling controls nicotine intake. Nature 471:597-601. CrossRef Medline

Hayes MR, Leichner TM, Zhao S, Lee GS, Chowansky A, Zimmer D, De Jonghe BC, Kanoski SE, Grill HJ, Bence KK (2011) Intracellular signals mediating the food intake-suppressive effects of hindbrain glucagon-like peptide-1 receptor activation. Cell Metab 13:320-330. CrossRef Medline

Hsu YW, Tempest L, Quina LA, Wei AD, Zeng H, Turner EE (2013) Medial habenula output circuit mediated by $\alpha 5$ nicotinic receptor-expressing GABAergic neurons in the interpeduncular nucleus. J Neurosci 33: 18022-18035. CrossRef Medline

Jackson KJ, Marks MJ, Vann RE, Chen X, Gamage TF, Warner JA, Damaj MI (2010) Role of alpha5 nicotinic acetylcholine receptors in pharmacological and behavioral effects of nicotine in mice. J Pharmacol Exp Ther 334:137146. CrossRef Medline

Jensen KP, DeVito EE, Herman AI, Valentine GW, Gelernter J, Sofuoglu M (2015) A CHRNA5 smoking risk variant decreases the aversive effects of nicotine in humans. Neuropsychopharmacology 40:2813-2821. CrossRef Medline
Morton G, Nasirova N, Sparks DW, Brodsky M, Sivakumaran S, Lambe EK, Turner EE (2018) Chrna5-expressing neurons in the interpeduncular nucleus mediate aversion primed by prior stimulation or nicotine exposure. J Neurosci 38:6900-6920. CrossRef Medline

Saccone SF, Hinrichs AL, Saccone NL, Chase GA, Konvicka K, Madden PA, Breslau N, Johnson EO, Hatsukami D, Pomerleau O, Swan GE, Goate AM, Rutter J, Bertelsen S, Fox L, Fugman D, Martin NG, Montgomery GW, Wang JC, Ballinger DG, et al. (2007) Cholinergic nicotinic receptor genes implicated in a nicotine dependence association study targeting 348 candidate genes with 3713 SNPs. Hum Mol Genet 16:36-49. CrossRef Medline

Sherva R, Wilhelmsen K, Pomerleau CS, Chasse SA, Rice JP, Snedecor SM, Bierut LJ, Neuman RJ, Pomerleau OF (2008) Association of a single nucleotide polymorphism in neuronal acetylcholine receptor subunit alpha 5 (CHRNA5) with smoking status and with "pleasurable buzz" during early experimentation with smoking. Addiction 103:1544-1552. CrossRef Medline
Stevens VL, Bierut LJ, Talbot JT, Wang JC, Sun J, Hinrichs AL, Thun MJ, Goate A, Calle EE (2008) Nicotinic receptor gene variants influence susceptibility to heavy smoking. Cancer Epidemiol Biomarkers Prev 17:35173525. CrossRef Medline

Tammimäki A, Herder P, Li P, Esch C, Laughlin JR, Akk G, Stitzel JA (2012) Impact of human D398N single nucleotide polymorphism on intracellular calcium response mediated by $\alpha 3 \beta 4 \alpha 5$ nicotinic acetylcholine receptors. Neuropharmacology 63:1002-1011. CrossRef Medline

Tuesta LM, Chen Z, Duncan A, Fowler CD, Ishikawa M, Lee BR, Liu XA, Lu Q, Cameron M, Hayes MR, Kamenecka TM, Pletcher M, Kenny PJ (2017) GLP-1 acts on habenular avoidance circuits to control nicotine intake. Nat Neurosci 20:708-716. CrossRef Medline

Wolfman SL, Gill DF, Bogdanic F, Long K, AlHasani R, McCall JG, Bruchas MR, McGehee DS (2018) Nicotine aversion is mediated by GABAergic interpeduncular nucleus inputs to laterodorsal tegmentum. Nat Commun 9:2710. CrossRef Medline 